\title{
MORE THAN A MEDICAL CONDITION: QUALITATIVE ANALYSIS OF MEDIA REPRESENTATIONS OF DEMENTIA AND ALZHEIMER'S DISEASE ${ }^{1}$
}

\author{
ANNA ŠESTÁKOVÁ and JANA PLICHTOVÁ
}

\begin{abstract}
The aim of our research is to explore how Alzheimer's disease and dementia are represented in the Slovak media. Data consisted of text documents from the Newton media database. Search criteria included TV, radio, print and web sources that mentioned the words "Alzheimer" and "dementia" between 2015 and 2018. A thematic discourse analysis was applied in order to identify the themes and their mutual semantic relations. The analysis was focused primarily on the headlines $(n=227)$. The results show that the biomedical perspective currently dominates at the expense of a socio-psychological one. Persons with Alzheimer's disease and dementia are represented as tragic cases and victims of a cruel disease. Responsibility for care and prevention is individualized. Our findings suggest that a new perspective is needed. Such an approach should recognize the dignity and humanity of persons with Alzheimer's disease and dementia despite their cognitive deficits and respect their socio-psychological needs.

Keywords: dementia; Alzheimer's disease; social representations; media.
\end{abstract}

We've all forgotten something. We've forgotten the most important thing. We've lost the memory of our humanity. ${ }^{2}$

\section{Introduction}

In medicine, the term dementia is used to describe symptoms of varying disorders that impair the human brain and occur most commonly but not uniquely in older people (WHO, 2017). Dementia is linked to many conditions including Alzheimer's disease (AD), vascular dementia, dementia with Lewy bodies, and frontotemporal dementia (WHO \& ADI, 2012).

$\mathrm{AD}$ is a type of dementia that involves the depletion of neurotransmitters and the development of senile plaques and neurofibrillary tangles, resulting in a significant loss of

\footnotetext{
1 This study was supported by the Slovak Research and Development Agency under the Contract APVV-17-0536.

2 "An evening with dementia" by Trevor T. Smith.
} 
neurons in the brain over the course of the disease (WHO \& ADI, 2012). Since the 1970s, when the term Alzheimer's disease became more generally acceptable over the older term senility (Chaufan, Hollister, Nazareno \& Fox, 2012), it has become a powerful label with a variety of cultural meanings. It is therefore necessary to consider how these changes in scientific discourse have been interpreted by the media and transformed into media representations of dementia and $\mathrm{AD}$.

\section{The theory of social representations and the role of the media}

The theory of social representations (TSR) describes how everyday knowledge, also known as "common sense", is socially created and shared in a given social or cultural sphere. Social representations are systems of concepts, values, and practices with two functions: (1) to establish an order which will enable individuals to orient themselves in their surroundings and (2) to enable communication by creating a code for naming and classifying the various aspects of the world (Moscovici, 1973).

The theory distinguishes two main communicative processes by which scientific concepts become "common sense": anchoring and objectification. Anchoring is a communicative process through which new phenomena or concepts are placed in the matrix of a local culture (Moscovici, 2000). Emotional anchoring refers to a process, where each phenomenon is represented either with negative or positive values and emotions. Objectification is the process of transforming an abstract concept into something that can be perceived by our senses in a material world (Moscovici, 2000).

As a prominent form of social communication, the media have the power to produce reality, and therefore the messages they convey should be carefully analyzed. TSR is highly relevant in media studies, as it offers a theory-based approach to studying how ideas are communicated and transformed into common sense, "how the media naturalize social thinking and generate collective cognitions" (Höijer, 2011, p. 3). However, TSR has been criticized for ignoring questions of power (see e.g. Voelklein \& Howarth, 2005). It could therefore, be usefully combined with critical discourse analysis.

According to van Dijk (1988), news production is a form of discourse processing. Abstract concepts are anchored in and objectified through expressive language, typically including metaphors and other rhetorical devices, in order to make them more comprehensible and tangible to lay audiences. Actor visibility and responsibility is displayed through agency, which can be directly expressed or suppressed through the use of passive sentences (see also Plichtová, 2010). Hence, discourse analysis has the potential to reveal valuable insights about media discourses on health and illness.

Although social representations of mental illnesses have been systematically studied since the 1970s (see e.g. Herzlich, 1973; Jodelet, 1989), research on media representations of dementia and $\mathrm{AD}$ is a relatively recent phenomenon. Kirkman (2006) found that the media remain a powerful transmitter of stereotypes, representing people with $\mathrm{AD}$ as victims of the disease. Other studies have found that dementia is predominantly represented as the loss of self (van Gorp \& Vercruysse, 2012). A "panic-blame" discourse which combines the rhetoric of panic and tragedy with individualized responsibility for dementia has been identified by Peel (2014). Zeilig (2013) who analyzed cultural narratives found that dementia is frequently associated 
with metaphors of crisis, war, natural disaster and a living death. Overall, it can be concluded that media representations of dementia and AD are predominantly negative (Peel, 2014).

\section{The aim of the empirical study}

There is a lack of research on media representations of dementia and Alzheimer's disease in the Slovak context. The present study is an attempt at filling this gap. The aim of this paper is to analyze (1) which representations of dementia and AD are created and shared by the media, (2) which topics are thematized and which are omitted, (3) how the themes are mutually related, (4) how objectification and anchoring are accomplished by the media and (5) to suggest the potential implications of the identified media representations.

\section{Method}

The choice of methodology was determined by TSR. A thematic analysis within a constructionist framework has been conducted in order to identify the themes ${ }^{3}$, and their mutual semantic relations. The study was also informed by critical discourse analysis (van Dijk, 1988; Fairclough, 1995; Wodak, 1999), which represents an important line of research regarding the study of media discourse. In the literature (see e.g. Singer \& Hunter, 1999; Peel, 2014) it is fairly common to find a combination of thematic and discourse analysis, as a simple thematic analysis does not allow the researcher to make claims about the language used, let alone about broader societal and political contexts. Adopting a critical approach was particularly important in the present study as these approaches increase awareness of power issues surrounding dominant representations and provide opportunities for change and resistance (Reisigl \& Wodak, 2001).

Our analysis was primarily focused on headlines. Headlines are particularly revealing of social and cultural representations because they depend on the reader instantly recognizing the cultural references. Moreover, they reach an audience considerably wider than one consisting of those who read the articles (Develotte \& Rechniewski, 2001). As highlighted by van Dijk (1988), the headline marks the preferred reading of the whole article and offers rich material for analysis.

\section{Corpus of data}

The data corpus consisted of TV, radio, print, and web documents from the Newton media database $^{\mathrm{TM}}$ (Table 1). Two search terms were selected: Alzheimer and dementia. Documents written in Slovak and published between the beginning of 2015 and the end of 2018 were

\footnotetext{
3 Whenever themes are mentioned in the study, it is in the context of the results of the empirical analysis. Themata as defined by Marková (2000) are basic pre-categorizations (prototypes of commonsense knowledge) that are anchored in the collective memory of a society. Unlike themata, themes have no generative and normative power nor are they antithetical couples (e.g. dyads such as health/illness; life/death). Therefore, a distinction needs to be made between themes as results of a thematic analysis in qualitative research and a few basic underlying themata which generate and structure these themes (see also Liu, 2004).
} 
selected. All texts were checked for relevancy. Articles not primarily concerned with dementia or AD were excluded. Duplicates (texts that were identical, with the same headline or minor changes in the headline) were rejected as well. However, articles appearing under different titles in various sources (i.e. several web pages or print periodicals), were retained. The final data corpus (after excluding the items that did not match the aforementioned criteria) consisted of 227 documents.

Table 1. Description of the data corpus

\begin{tabular}{|c|c|c|}
\hline Source & Number of headlines $(\mathbf{N}=\mathbf{2 2 7})$ & $\mathbf{\%}$ \\
\hline Web & 144 & 63.4 \\
\hline Print & 70 & 30.8 \\
\hline TV & 8 & 3.5 \\
\hline Radio & 2 & 0.9 \\
\hline Other (e.g. a press agency) & 3 & 1.4 \\
\hline
\end{tabular}

\section{Analysis procedure}

The analysis was performed in several steps: first a database of the key terms AD and dementia was created, then each text was enumerated and categorized according to type of media. The texts were read carefully by both researchers, sorted according to genre (e.g. a story) and reduced to a short summary. That way we were able to generate an overall picture of how the media communicate about dementia and AD.

Each headline was analyzed in terms of the use of rhetorical devices (metaphors, metonyms, etc.), sentence structure (active/passive, position of the various actors in the discourse, attributed responsibility, etc.) and forms of anchoring and objectification by both researchers independently (researcher triangulation). The analysis of emotional anchoring was based on the identification of the emotional valence of rhetorical devices which were classified as neutral, positive, negative or ambivalent. Consequently, each headline was categorized according to topic (e.g. prolongation of life) and then according to main theme (e.g. bioethical questions and aging). In the final step, the relationships between the themes were analyzed based on the overlap between the topics, resulting in a visual representation of the thematic map (see Figure 1). Marginal and main themes was were distinguished based on their prevalence (frequency) in the data. Marginal themes occurred no more than 3 times while main themes occurred at least 10 times. The analysis was primarily data-driven and inductive.

In order to reduce individual differences in judgement we used the consensual qualitative research method (Hill, Thompson, \& Williams, 1997), in which two or more coders code and categorize the data. To gain some additional feedback, the results of the analysis were presented to the panel of experts in clinical and social psychology. Their comments and reflections were considered and taken into account in the final step of the analysis. 


\section{Results}

The results section is organized as follows: first, we present some general information about the occurrence of headlines and key terms. We then proceed to the analysis of the rhetorical devices, followed by the results of the thematic discourse analysis. Finally, the processes of emotional anchoring and objectification are described in relation to the themes identified.

\section{Occurrence of the topic of $\mathrm{AD}$ and dementia in the media}

Within the four-year period, 227 articles were published (after discarding the duplicates and irrelevant texts), which makes for a frequency of nearly 5 articles per month. As expected, Alzheimer's disease or "Alzheimer" appeared in headlines with the highest frequency (75), followed by dementia (53), brain (22), memory (9), and aging (9). Therefore, we paid special attention to rhetorical devices used in relation to these terms.

\section{The analysis of rhetorical devices}

There was not much difference between the representations of dementia and those of Alzheimer's disease (Table 2). Dementia was predominantly described using emotional

Table 2. Representations of Alzheimer's disease and dementia

\begin{tabular}{|c|c|c|}
\hline Alzheimer's disease & Dementia & Not specified (or both) \\
\hline \multirow[t]{2}{*}{ destroys people } & destroys people & destroys people \\
\hline & destroys the brain & destroys brains \\
\hline a race against time & a time-bomb & \\
\hline $\begin{array}{l}\text { the most cunning form of } \\
\text { dementia }\end{array}$ & is cunning & cunning, deceitful illness \\
\hline hides from doctors & $\begin{array}{l}\text { hides behind the symptoms of } \\
\text { other diseases }\end{array}$ & $\begin{array}{l}\text { an invisible enemy } \\
\text { a silent epidemic }\end{array}$ \\
\hline \multirow[t]{3}{*}{$\begin{array}{l}\text { must be scared off } \\
\text { must be defeated }\end{array}$} & $\begin{array}{l}\text { can be fought against } \\
\text { must be collectively resisted } \\
\text { must not be given a chance }\end{array}$ & \\
\hline & \begin{tabular}{|l} 
cruel diagnosis \\
\end{tabular} & cruel truth \\
\hline & is devastating & $\begin{array}{l}\text { hurts us where we are most } \\
\text { vulnerable }\end{array}$ \\
\hline $\begin{array}{l}\text { a scarecrow } \\
\text { haunts our society } \\
\text { haunts a big section of the } \\
\text { population }\end{array}$ & & $\begin{array}{l}\text { one of the ten most aggressive } \\
\text { killers in the world } \\
\text { a scary illness } \\
\text { a diagnosis that emanates fear }\end{array}$ \\
\hline is coming for its victims & & lurks and ambushes \\
\hline
\end{tabular}


adjectives such as scary, cunning, and deceitful, while AD was explicitly referred to as "the most cunning form of dementia". Through the use of personification, the media created a fictitious entity: a powerful, insidious being, a scarecrow, an invisible enemy, or aggressive killer always looking for its victims. Both $\mathrm{AD}$ and dementia were portrayed as a real person, or rather a dangerous monster - threatening, attacking, destroying lives and haunting modern society. Despite the fact that this enemy "hides even from the doctors", potential victims are supposed to watch out and "not give dementia a chance".

The processes in the brain are described as mysterious, secret and hidden (Table 3). The brain is portrayed as a miracle, a secret, and a mystery. A healthy brain is compared to a well-functioning machine. However, the functionality of the brain should not be taken for granted, as both the brain and memory are prone to injury, illness, and malfunction. Therefore, readers are strongly urged to look after their memory and train it like a muscle. By following the recommendations, readers can protect their brains and slow down or even stop the process of aging.

Table 3. Representations of memory, brain and aging

\begin{tabular}{|l|l|l|}
\hline Memory & Brain & Aging \\
\hline should work & has secret connections & can be accelerated/decelerated \\
\hline should serve us & has hidden ridges & can be slowed down \\
\hline has problems & can be rejuvenated & can put the brakes on \\
\hline has secrets & needs to be active & \\
\hline has outages & needs to be protected & \\
\hline needs to be looked after & can be destroyed & \\
\hline must be forced to work & & \\
\hline must be trained & & \\
\hline our biggest treasure & & \\
\hline
\end{tabular}

\section{Description of themes}

Figure 1 is a map of the identified themes and their mutual relations. The main idea of each theme is briefly described. Unique themes (marginal but present nonetheless) are marked by a dotted line. The themes are described in more detail in the section below.

\section{Alzheimer's and dementia as a medical diagnosis}

This theme reflects the scientific turn in which the older label of senile dementia was replaced with the modern diagnostic label of Alzheimer's disease and other types of dementia. A sharp distinction is made between healthy and pathological aging - there is no such thing as the natural decline of cognitive abilities because all types of decline are 


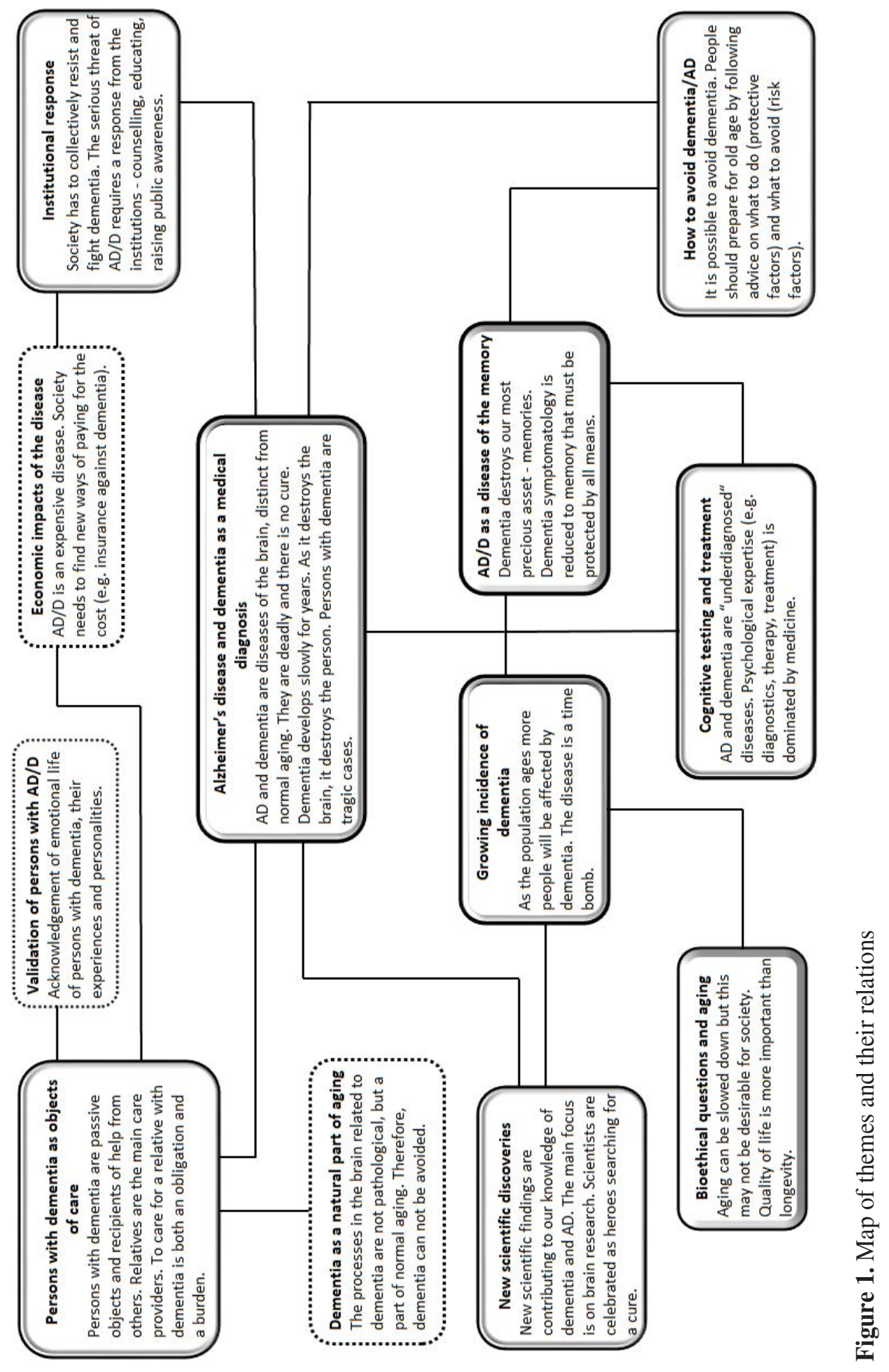


attributed to pathological processes in the brain. Persons with dementia were represented in ways that mirrored the emphasis on symptoms, decline, and the tragic aspects of the disease. The media paid more attention to rare cases of young dementia, presenting them as more shocking and interesting for its audience:

The heart-breaking story of young Becky (32), at this young age she has been given a cruel diagnosis: DEMENTIA.4 The horrors of dementia were repeatedly described using expressions such as cruel diagnosis, devastating story, grim prognosis. Another group affected by dementia with high visibility in the media were foreign celebrities. In their case, dementia was displayed as the loss of previous social status and achievement.

\section{Growing incidence of dementia}

The tragic depiction of the disease was reinforced by the notion that both dementia and Alzheimer's disease are on the increase in the world. The prevalence of dementia was connected to certain countries (rich), gender (females) and age, as well as certain lifestyles. The growing prevalence of dementia was illustrated by headlines such as 50 million people suffer from Alzheimer's disease all over the world. ${ }^{5}$

Compared to the tragic rhetoric of patient stories, estimates of dementia incidence were clearly anchored in the emotion of panic:

Alzheimer's disease is winning the race with cancer: scientists are unable to find a cure. ${ }^{6}$ Other headlines compared $\mathrm{AD}$ and dementia to a ticking time-bomb and a catastrophe awaiting modern societies if a cure is not found. Dementia, one of the ten most aggressive killers in the world ${ }^{7}$, haunts the population and the demographics leave little room for optimism.

\section{Dementia and $A D$ as a disease of the memory}

Although dementia and AD affect all the cognitive functions, such as perception, executive functions, speech and spatial orientation, AD and dementia were almost exclusively constructed as a memory problem. Memory was further reduced to the brain processes, since the terms brain and memory were used interchangeably. The media used memory as a way of simplifying the complex dementia symptomatology. Although the difficulty of identifying symptoms of dementia was acknowledged, readers were nonetheless expected to recognize them.

\section{Diagnostics and treatment}

The emphasis on symptoms was not mirrored in the headlines related to diagnostics. Only two headlines mentioned diagnostic tools, such as cognitive tests. If a test was mentioned,

4 Source: web, pluska.sk. Date: 4.9. 2017

5 Source: web, hlavne.sk. Date: 20.9. 2018

6 Source: web, zivot.sk. Date: 14.5. 2018

7 Source: print, Zdravie rodiny. Date: 20.10. 2017 
it was usually a short test included in the article so readers could test themselves for dementia symptomatology. This low interest in diagnostics is surprising considering the progress in developing modern diagnostic tools such as genetic tests or neuroimaging methods. Headlines such as Alzheimer's disease is largely underdiagnosed in Slovakia ${ }^{8}$ acknowledged that there is a problem regarding diagnosis of dementia and AD in Slovakia; however, the use of the passive form of the sentence enabled them to avoid mentioning the responsible agents.

Overall, psychological expertise including diagnostics, therapy, and treatment was dominated by medicine. The importance of so-called non-pharmacological (psycho-social) therapy methods was underplayed by the choice of vocabulary. For example, the headline Old people are being treated with memories ${ }^{9}$ is supposed to refer to reminiscence therapy. Similarly, the role of clinical psychologists was overlooked, and references were made to experts, specialists, or memory trainers.

\section{New scientific discoveries}

Researchers were not only the most visible actors and winners of prestigious awards but were also glorified and celebrated as heroes. The achievements of science were anchored in the positive emotions of pride and nationalism:

\section{Slovaks will defeat Alzheimer's ${ }^{10}$ \\ We want to be the first in the world ${ }^{11}$}

Scientific progress was seen as the only hope for discovering the causes of dementia and finding a cure. While some headlines stated that a cure for dementia and AD had already been found, others were trying to convince readers that it would be possible to cure dementia within 10 years, and yet others thought a cure would never be found. There was no consensus about the causes and risk factors associated with $\mathrm{AD}$ or other forms of dementia. Viruses, toxic substances, vaccines, and head trauma were considered causal factors. Moreover, research on genetic and environmental factors (such as air pollution) contradicted the notion that healthy aging is completely in the hands of an individual.

\section{Bioethical questions and aging}

Interestingly, science was expected to find a cure not only for dementia but also for old age. A couple of articles dealt with the possibility of slowing down or even completely stopping aging, using speed metaphors and images of car brakes, decelerating and accelerating processes in the brain. There was uncertainty over whether society would really want such a remedy against old age:

\footnotetext{
8 Source: print, Zdravotnícke noviny. Date: 10.11. 2016

9 Source: print, Kysucké noviny. Date: 5.5. 2015

${ }^{10}$ Source: print, HN magazín. Date: 27.5. 2016

${ }^{11}$ Source: TV, TV JOJ. Date: 14.5. 2016
} 
It is possible to stop aging: but does humanity even want to ${ }^{{ }^{12}}$

Scientists warn: it is possible to slow down aging but the consequences would be catastrophic ${ }^{13}$

In the first headline, the undesirability of stopping the aging process is reflected in question form, while the next one directly indicates that such an attempt would be followed by catastrophic consequences. A direct quote is used strategically to support the claim with the authority of science. Hope for a cure for old age may be seen as a product of an extremely youth-oriented society that does not want to age but at the same time realizes that slowing down aging will not be sustainable.

\section{Prevention - how to avoid dementia and $A D$}

Despite the strong association between old age and dementia, older people were expected to avoid dementia by engaging in all sorts of preventative behaviors. The articles either tried to advise readers on how to protect themselves or to warn them about what to avoid. The imperative style of the headlines could be perceived as almost directly attacking the reader:

These everyday habits increase your risk of getting dementia: avoid them! $!^{14}$

Don't give cunning dementia a chance: What to eat and what to avoid? You may have been making this big mistake for years ${ }^{15}$

These examples show how the reader is clearly made responsible for allowing the disease to develop by making serious lifestyle mistakes. Such a depiction is in stark contrast with other themes that depict dementia as a mysterious, unstoppable force against which individuals are powerless. While some articles focused on one factor only (such as beer, sugar), others suggested that successful prevention involved several factors, including diet and cognitive, physical and social activity (Table 4).

\section{Institutional response}

The theme of institutional response was predominantly concerned with activities on a societal level such as conferences, campaigns and counselling. The need to resist and embrace a fighting attitude was reinforced by war metaphors and appeals such as Let's not fear dementia! ${ }^{16}$ Paradoxically, fear-mongering was sometimes used to highlight the seriousness of the issue and the need for immediate action: The silent epidemy is hurting us in the most vulnerable place: Experts have started a free hotline ${ }^{17}$.

Sentences concerning experts were usually active, using verbs such as demonstrate, request, educate, advise, discover and warn. For example, the headline Experts will

\footnotetext{
${ }^{12}$ Source: web, pravda.sk. Date: 9.10 .2017

${ }^{13}$ Source: web, topky.sk. Date: 11.10. 2017

${ }^{14}$ Source: web, plnielanu.zoznam.sk. Date: 9.9. 2017

${ }^{15}$ Source: web, beauty.sk. Date: 2.11. 2016

${ }^{16}$ Source: web, facebook.com. Date: 12.3. 2018

${ }^{17}$ Source: web, zoznam.sk. Date: 8.1. 2018
} 
Table 4. Preventative measures recommended to the readers

\begin{tabular}{|c|c|c|}
\hline & Single factor & Complex prevention \\
\hline \multirow{7}{*}{$\begin{array}{l}\text { Recommended } \\
\text { in the headline }\end{array}$} & Food (not specified) & Sport and mental activity \\
\hline & Beer/alcohol & Sport, nutrition, and friends \\
\hline & Diet & Lifestyle changes \\
\hline & Beverages (not specified) & \\
\hline & Coffee & \\
\hline & Mental activity & \\
\hline & Herbs (not specified) & \\
\hline \multirow{16}{*}{$\begin{array}{l}\text { Recommended } \\
\text { in the text }\end{array}$} & Vitamins E, D & Active lifestyle \\
\hline & Sport & $\begin{array}{l}\text { Nutrition, social life, positive thinking, physical } \\
\text { and mental activity, hobbies }\end{array}$ \\
\hline & Herbs & Sport and relationships \\
\hline & Nutrition & $\begin{array}{l}\text { Active aging, cognitive and physical activities, } \\
\text { social support, and communication }\end{array}$ \\
\hline & $\begin{array}{l}\text { Moderate alcohol } \\
\text { consumption }\end{array}$ & $\begin{array}{l}\text { Physical and mental activities, Mediterranean } \\
\text { diet, social life }\end{array}$ \\
\hline & Coffee & $\begin{array}{l}\text { Mental and physical activities, vitamins and } \\
\text { minerals, antioxidants }\end{array}$ \\
\hline & $\begin{array}{l}\text { Nutrition - lean meat } \\
\text { (poultry, calcium, } \\
\text { vitamins B and D) } \\
\end{array}$ & Mental and physical activities, rest \\
\hline & Probiotics & $\begin{array}{l}\text { Sport, walking, nutrition (carrots, pineapple, } \\
\text { avocado, strawberries, blackberries, onions, } \\
\text { nuts, ginger, bananas) }\end{array}$ \\
\hline & $\begin{array}{l}\text { Nutrition (eggs, cheese, } \\
\text { yoghurt, curd cheese) }\end{array}$ & Water, green tea, turmeric milk, mental activity \\
\hline & & $\begin{array}{l}\text { Fruit, vegetables, nuts, poultry, fish, sunshine } \\
\text { exposure, physical activity }\end{array}$ \\
\hline & & $\begin{array}{l}\text { Beer, vitamin B, protein, fiber, antioxidants, } \\
\text { water, social life }\end{array}$ \\
\hline & & $\begin{array}{l}\text { Sport, healthy lifestyle, minimal stress, nutrition } \\
\text { (vegetables, vitamins, minerals, antioxidants) }\end{array}$ \\
\hline & & Nutrition, sport, healthy environment \\
\hline & & Cognitive training and social contact \\
\hline & & Regular physical activity, low fat diet, no smoking \\
\hline & & $\begin{array}{l}\text { Healthy and balanced nutrition (fruit, } \\
\text { vegetables, lean meat, nuts and seeds), no } \\
\text { alcohol, no smoking, small portions }\end{array}$ \\
\hline
\end{tabular}


demonstrate how to work with Alzheimer sufferers ${ }^{18}$ shows the active role of the experts contrasted with the passive role of persons with Alzheimer's, who are labelled in terms of their diagnosis. Most of these activities were related to non-governmental organizations (Memory Centrum, Alzheimer's society). Activities by other institutions such as state or public institutions were hardly mentioned.

\section{Persons with dementia as objects of care}

The need to empathize and care for persons with dementia was acknowledged, as they were constructed as objects of pity. However, persons with dementia were typically cast in the passive role of object and recipient of help from others:

We have been caring for people with Alzheimer's disease for over 6 years ${ }^{19}$

The notion that a caring relative is expected to put his or her wishes aside was raised indirectly, for example in the form of a story: Linda wanted to leave her unfaithful husband: when she learned the cruel truth, it forced her to stay with him forever ${ }^{20}$. Advice and tips on how to care for a person with dementia were mostly aimed at informal caregivers, while the topic of institutional care was reduced to information about new and usually private nursing homes such as in the headline: A life with dignity: an excellent center is being built for people with Alzheimer's in France ${ }^{21}$. Whether a life with dignity is possible in the system of institutional care in Slovakia was not clear.

\section{Dementia as a natural part of aging}

In this theme the notion that dementia is a pathological process is rejected and questions are raised about how dementia can be avoided in old age. The older term senile dementia is preferred over the modern label Alzheimer's disease and other forms of dementia. Dementia is viewed as a natural part of aging, as a price we have to pay for living much longer than in the past. Therefore, there is no clear distinction between healthy seniors and people with dementia. Since the symptoms are considered a natural part of aging, the disease is described in much less alarming and catastrophic terms.

\section{Validation of persons with $A D$ and dementia}

This theme concerned the importance of relationships and communication, and respecting the subjectivity, emotions, and needs of persons with dementia. The tragic rhetoric of the main dementia discourse was largely avoided. Instead, the articles were trying to elicit audience empathy by making the experience of dementia more comprehensible. Headlines such as

\footnotetext{
${ }^{18}$ Source: web, pnky.sk. Date: 5.11. 2015

${ }_{19}$ Source: web, 24hod.sk. Date: 12.9. 2016

${ }^{20}$ Source: web, casprezeny.sk. Date: 22.7. 2015

${ }^{21}$ Source: web, Plus7dni.pluska.sk. Date: 2.7. 2018
} 
How does a person with Alzheimer's disease feel?22 or

They know they are forgetting ${ }^{23}$

highlighted the fact that people with dementia are still able to feel and think about their symptoms and problems. Persons with dementia are viewed as united in body and mindeven if their cognitive abilities decline, they are still able to express themselves, as they have emotions and bonds with other people.

\section{The economic impacts}

The media largely avoided the topic of the economic impacts of dementia. Financial issues related to dementia care were addressed indirectly, for example by providing information about the new dementia insurance. In Japan, people are now able to get insurance against dementia to avoid the high costs that come with the disease. As dementia is one of the costliest diseases, society has to find new creative ways of how to deal with the costs of care and treatment.

\section{Processes of anchoring and objectification}

\section{Emotional anchoring}

The media attached various emotions to the abstract phenomenon of dementia and AD. Surprisingly, these were not all negative. Positive emotional anchoring was related to prevention (it is possible to avoid dementia), scientific discoveries (a cure for dementia will soon be found), care (improving patient quality of life) and institutional response to dementia ("resisting" dementia). The negative anchoring was typically used in relation to themes of dementia such as medical diagnosis and epidemiology (growing incidence of dementia). Also, the majority of the stories about persons with dementia were anchored in negative emotions.

\section{Objectification}

The abstract concepts of dementia and $\mathrm{AD}$ were most often objectified through an image of a degenerating brain, destroyed by plaques and tangles. In some themes, such as prevention, dementia was objectified by both the brain and the body (what is good for the body is also good for the mind). The fight against the disease was objectified by references to researchers, institutions, and special days and events (such as Alzheimer's day/month). The disease itself was objectified by references to persons with dementia, including ordinary people and celebrities.

${ }^{22}$ Source: web, webnoviny.sk. Date: 29.9. 2016

${ }^{23}$ Source: web, dennikN.sk. Date: 8.9. 2017 


\section{Absent themes}

Several themes were absent. The media were completely silent about healthcare professions, other than researchers and physicians. Neither were the economic and social impacts of dementia on families and individuals discussed. There was no analysis of the accessibility and quality of health and social services and there was no discussion about policies affecting the system of care for older people. Issues regarding the stigma, dehumanization, and exclusion of persons with dementia were omitted, and the problems were never discussed from the perspective of human rights violations. The media largely avoided the topic of assisted suicide as a possible choice for persons with dementia. No attention was given to discrimination against persons with dementia or older people in general.

\section{Discussion}

As far as we know, our study represents the first attempt to describe media representations of dementia and Alzheimer's disease in a Slovak context. In line with previous research, our analysis shows that both dementia and $\mathrm{AD}$ are constructed as a catastrophe (see for e.g. Behuniak, 2011; Brannelly, 2011; George, 2010). Similar meanings associated with dementia and AD can mainly be explained by historical reasons. Since the newly founded advocacy groups wanted to avoid spreading their resources by targeting multiple diseases, they decided to focus on $\mathrm{AD}$ (the most prevalent form of dementia), which consequently became the most well-known type (Chaufan et al., 2012).

While we have known about the negative emotional anchoring of dementia representations for a long time, other studies have not identified the positively anchored representations. Our analysis shows that positive anchoring is present, even though it is more characteristic for some themes than for others. For example, the topic of scientific discoveries creates an opportunity for enhancing national pride and nationalism by celebrating Slovak scientists. This finding is similar to the findings of Berglez, Höijer, and Olausson (2009) who identified the theme of self-glorification and nationalism in the discourse on environmental issues. The celebration of science can be attributed to the influence of the biomedical model which explains dementia in terms of brain disease and therefore prioritizes research into its causes and the search for a possible cure.

Positive anchoring was also evident in the theme of prevention, similar to that identified by Peel (2014). Despite being more positive and empowering than the discourse of tragedy, the preventative discourse is also problematic. By attributing responsibility for cognitive health to the individual, the individual can be blamed for the failure to protect it (Peel, 2014). The emphasis on prevention can be seen as an attempt to take back control over a seemingly hopeless and uncontrollable disease. Real or not, the notion that it is possible to avoid dementia serves as a defense mechanism for society.

Our results differ from previous research especially regarding the financial costs related to dementia and AD. Contrary to previous findings, the risk of an aging population was never explicitly described in financial terms. McLeod (2014) described "the rising tide" discourse in a similar way to our theme of the growing prevalence that combines apocalyptic images with economic rhetoric. Similarly, McFadden and McFadden (2011) 
observed that dementia is mainly portrayed through the repeated notion of how much it will cost the economy. Since both dementia and AD are extremely 'expensive' diseases, the fact that the financial aspects were avoided signals that it might be considered a taboo topic by Slovak journalists.

In contrast to the highly visible researchers, the invisibility of other health and social care professions in the media is an indicator of their lower social status and the lack of adequate financial support and recognition. Persons with dementia and their relatives typically received media attention only when their experiences were interesting enough to be considered newsworthy - such as young people and celebrities with dementia. The fact that most stories of people with dementia were from abroad indicates that there is a stigma associated with publicly disclosing a dementia diagnosis in Slovakia.

\section{Potential implications}

Our findings have several possible implications. Firstly, the results show that the responsibility for dementia prevention and care is individualized. It is very likely that the individualization of responsibility places responsibility on the shoulders of families, who are expected to provide specialized care without much knowledge, support or training.

Similarly, the focus of prevention lies on individual lifestyle issues. The media do not take into account that some lifestyle choices may not be available to the lower strata of the population nor that some risk factors (such as air pollution) can hardly be avoided on the individual level. Systemic changes such as policies that ameliorate poverty and tackle the lack of healthcare, limited access to higher education, inadequate access to good quality food, the consequences of climate change and unhealthy living conditions in modern societies could effectively protect "many brains" (Lemke, 2002).

Lastly, our analysis showed that most of the institutional activities that are visible in the media are provided by non-governmental organizations. Organizations such as Memory Centrum offer education and training, raise public awareness, organize support groups for people with dementia and their families, provide counselling and much more, while the responsibilities of the public institutions are silently disappearing. This model is neither sufficient nor sustainable and requires serious re-evaluation.

\section{Limitations and future studies}

Biased titles or titles that do not accurately reflect the content of the article are not rare in media reports. It is questionable whether the themes identified in the headlines were representative of the whole data corpus. Since the images and illustrations, as well as the other information (e.g. the placement of the article in the newspaper, size of the headline, etc.) were not part of the media database, they could not be included in the analysis. This is an important omission, given that these characteristics contain important information about the relevance of the news report (Plichtová, Lášticová, \& Petrjánošová, 2009). Future research should study how media representations are translated into the lay representations of the disease, as well as the differences between dementia representations of different social groups (e.g. professionals, carers, people with dementia and the lay public). 


\section{Conclusion}

The media play a crucial role in shaping issues within society and setting the boundaries of what is talked about and how it is talked about. Our study has found that the media largely adopted a medical perspective, while neglecting other perspectives and aspects of life with dementia. Such a skewed perspective could lead to the dehumanization and exclusion of people with dementia. It is our responsibility as social actors to rethink and transform collective cognitions of dementia if they are stigmatizing and harmful. We hope that by providing a detailed exploration of media representations of dementia and Alzheimer's disease in Slovakia, our study has contributed to this noble goal.

\section{References}

Behuniak, S. (2011). The living dead? The construction of people with Alzheimer's disease as zombies. Ageing \& Society, 31, 70-92.

Berglez, P., Höijer, B., \& Olausson, U. (2009). Individualisation and nationalisation of the climate issue. Two ideological horizons in Swedish news, climate change and the media. In T. Boyce and J. Lewis (Eds.), Media (pp. 211-223). New York: Peter Lang.

Brannelly, T. (2011). Sustaining citizenship: People with dementia and the phenomena of social death. Nursing Ethics, 18(5), 662-7.

Develotte, C., \& Rechniewski, E. (2001). Discourse analysis of newspaper headlines: A methodological framework for research into national representations. The Web Journal of French Media Studies, 4(1). Retrieved from http://wjfms.ncl.ac.uk/titles.htm

Fairclough, N. (1995). Media discourse. London: Longman.

George, D.R. (2010). Overcoming the social death of dementia through language. The Lancet, 376(9741), 586- 587.

Herzlich, C. (1973). Health and illness. A social psychological analysis. London: Academic Press.

Hill, C., Thompson, B., \& Williams, E. (1997). A guide to conducting consensual qualitative research. The Counseling Psychologist, 25(4), 517-572.

Höijer, B. (2011). Social representations theory. A new theory for media research. Nordicom Review, 32, 3-16.

Chaufan, C., Hollister, B., Nazareno, J., \& Fox, P. (2011). Medical ideology as a double-edged sword: The politics of cure and care in the making of Alzheimer's disease. Social Science \& Medicine, 74(5), 788-795.

Jodelet, D. (1989). Folies et représentations sociales [Insanity and social representations]. Paris: PUF.

Kirkman, A.M. (2006). Dementia in the news: The media coverage of Alzheimer's disease. Australasian Journal on Ageing, 25(2), 74-79.

Lemke, T. (2002). Foucault, governmentality and critique. Paper presented at the Rethinking Marxism Conference, University of Amherst (MA). Retrieved from http://www.andosciasociology.net/ resources/Foucault $\$ 2 \mathrm{C}+$ Governmentality $\$ 2 \mathrm{C}+$ and + Critique+IV-2.pdf

Liu, L. (2004). Sensitising concept, themata and shareness: A dialogical perspective of social representations. Journal for the Theory of Social Behaviour, 34(3), 249-264.

Marková, I. (2000). Amédée or how to get rid of it: Social representations from a dialogical perspective. Culture and Psychology, 6(4), 419-460.

McFadden, S.H., \& McFadden, J.T. (2011). Aging together: Dementia, friendship and flourishing communities. Baltimore, MD: John Hopkins University Press.

McLeod, S. A. (2014). From the 'rising tide' to solidarity: Disrupting dominant crisis discourses in dementia social policy in neoliberal times. [Master thesis.] University of Victoria. Retrieved from 
https://dspace.library.uvic.ca/bitstream/handle/1828/5213/MacLeod_Suzanne_MSW\%20_2014. pdf?sequence $=1$ \&isAllowed $=\mathrm{y}$

Moscovici, S. (1973). Foreword. In C. Herzlich (Ed.), Health and illness: A social psychological analysis. London: Academic Press.

Moscovici, S. (2000). Social representations. Explorations in social psychology. Cambridge, UK: Polity Press.

Peel, E. (2014). 'The living death of Alzheimer's' versus 'Take a walk to keep dementia at bay': Representations of dementia in print media and carer discourse. Sociology of Health \& Illness, $36(6), 885-901$.

Plichtová, J. (2010). Kritická diskurzívna analýza: výzva sociálnej psychológii [Critical discourse analysis: a challenge for social psychology]. Československá psychologie, 54(4), 329-342.

Plichtová, J., Lášticová, B., \& Petrjánošová, M. (2009). Konštruovanie slovenskosti vo verejnom priestore [The construction of Slovakness in a public space]. Bratislava: Kabinet výskumu sociálnej a biologickej komunikácie SAV.

Reisigl, M., \& Wodak, R. (2001). Discourse and discrimination (Rhetoric of racism and antisemitism). London: Routledge.

Singer, D., \& Hunter, M. (1999). The experience of premature menopause: A thematic discourse analysis. Journal of Reproductive and Infant Psychology, 17(1), 63-81.

van Dijk, T.A. (1988). News as discourse. Hillsdale, NJ: Lawrence Erlbaum.

van Gorp, B., \& Vercruysse, T. (2012). Frames and counter-frames giving meaning to dementia: A framing analysis of media content. Social Science and Medicine, 74, 1274-1281.

Voelklein, C., \& Howarth, C. (2005). A review of controversies about social representations theory: A British debate. Culture \& Psychology, 11(4), 431-454.

Wodak, R. (1999). Critical discourse analysis at the end of the 20th century. Research on Language and Social Interaction, 32(1-2), 185-93.

World Health Organization \& Alzheimer's Disease International (2012). Dementia: A public health priority. Retrieved from http://www.who.int/mental_health/publications/dementia_report_2012/en/

World Health Organization (2017). Global action plan on the public health response to dementia 20172025. Retrieved from https://apps.who.int/iris/bitstream/handle/10665/259615/9789241513487-eng. pdf;jsessionid=76C1ED85C7F6A1445544A371B2B4BDF4?sequence=1

Zeilig, H. (2013). Dementia as a cultural metaphor. The Gerontologist, 54(2), 258-267.

Institute of Applied Psychology

Faculty of Social and Economic Sciences

Mlynské luhy 4

82105 Bratislava

Slovak Republic

Email: sestakova.anka@gmail.com

jana.plichtova@fses.uniba.sk 